\title{
Produtividade e proteína bruta de pastagens de capim elefante manejadas sob os sistemas agroecológico e convencional
}

\author{
Productivity and crude protein of elephant grass pastures managed under \\ agroecological and conventional systems
}

\author{
Clair Jorge Olivo ${ }^{I}$ Priscila Flôres Aguirre ${ }^{I I}$ Tiago Luís da Ros de AraújoiI \\ Michelle Schalemberg Diehl ${ }^{\text {II }}$ Cláudia Marques de Bem ${ }^{\text {II }}$ \\ Gabrielle Serafim ${ }^{\text {II }}$ Marcos da Rosa Correa ${ }^{\text {II }}$
}

\section{RESUMO}

O objetivo desta pesquisa foi avaliar a massa, o teor de proteína bruta da forragem e a taxa de lotação em pastagens de capim elefante em dois sistemas de produção. No sistema convencional, o capim elefante foi plantado em linhas afastadas a cada 1,2m. No sistema agroecológico, o capim foi plantado em linhas afastadas a cada $3 \mathrm{~m}$; no espaço entre as linhas, no período hibernal, foram semeados o azevém anual e o trevo vermelho e, no período estival, permitiu-se o desenvolvimento de espécies de crescimento espontâneo. Foram utilizados $150 \mathrm{~kg}^{\mathrm{de}} \mathrm{N} \mathrm{ha^{-1 } \mathrm { com }}$ fertilizantes químico e orgânico para os respectivos sistemas forrageiros. Foram usadas vacas em lactação que receberam complementação à razão de $0,9 \%$ do peso vivo. Para determinação do teor de proteína bruta, foram retiradas amostras simulando o pastejo. Valores similares foram observados quanto à composição estrutural do capim elefante em ambos os sistemas. Durante o período experimental, foram conduzidos oito e sete pastejos para os respectivos sistemas. Os valores médios de massa de forragem de pré-pastejo e da taxa de lotação foram de 3,7 e 4,8t ha $\mathrm{h}^{-1}$ e de 2,10 e 2,51UA ha a $^{-1}$ dia $^{-1}$. A pastagem sob sistema agroecológico apresenta melhor distribuição de forragem ao longo do ano. Teores elevados de proteína bruta foram observados no período hibernal, em ambos os sistemas forrageiros.

Palavras-chave: vacas leiteiras, Lolium multiflorum, Pennisetum purpureum, sistemas de produção, Trifolium pratense.

\section{ABSTRACT}

The objective of this research was to evaluate the forage mass, crude protein and stocking rate on elephantgrass pastures in two production systems. In the conventional system elephantgrass was planted in rows $1,2 \mathrm{~m}$ apart from each other. In the agroecological system elephant grass was planted in rows $3 m$ apart from each other. In the space between alleys, in cool season, annual ryegrass and red clover were introduced; allowing the development of spontaneous growing species in the warm season. It was applied $150 \mathrm{~kg}$ of $\mathrm{N} \mathrm{ha}^{-1}$ with chemical and organic fertilizers in the respective pastures. Holstein cows receiving $0.9 \%$ of body weight complementary concentrate feed were used. Hand-plucked samples were collected to analyze crude protein. Similar value was found in the structural components of elephantgrass pastures in both pasture systems. Eight and seven grazing cycles were performed during the experimental period for respective systems. The average dry matter value for pre-grazing and stocking rate were 3.7 e $4.8 \mathrm{tha}^{-1}$ and 2.10 e $2.51 \mathrm{AU} \mathrm{ha}^{-1}$ day $^{-1}$ for each respective systems. Agroecological system presents best forage distribution throughout the year. Higher values of crude protein of elephantgrass were observed in cool season in both systems.

Key words: lactating cows, Lolium multiflorum, Pennisetum purpureum, production systems, Trifolium pratense.

\section{INTRODUÇÃO}

O capim elefante (Pennisetum purpureum Schum.), que é uma gramínea perene de porte ereto, possui alto potencial de produção de forragem e de adaptação às condições climáticas predominantes em quase todo o País. Seu uso ocorre especialmente em pequenas e médias propriedades leiteiras, nas quais essa forrageira é estabelecida de forma singular, sendo utilizados, normalmente, níveis elevados de adubação química, especialmente nitrogenada. Nessa estratégia de produção convencional, baseada no rendimento do pasto, há elevação do custo de produção, distribuição inadequada da forragem no decorrer dos ciclos de

IDepartamento de Zootecnia, Universidade Federal de Santa Maria (UFSM), Santa Maria, RS, Brasil. E-mail: clairo@smail.ufsm.br.

Autor para correspondência.

IPrograma de Pós-graduação em Zootecnia, UFSM, RS, Brasil. 
pastejo, havendo, muitas vezes, degradação dos pastos. Também as pesquisas conduzidas com capim elefante referem-se, basicamente, à produção convencional. Estudos envolvendo essa forrageira sob as estratégias de produção agroecológica, orgânica, biodinâmica, consideradas mais sustentáveis (OLIVO et al., 2007), são escassos.

Dentro do proposto pela Instrução Normativa no 46/2011 do Ministério da Agricultura Pecuária e Abastecimento (MAPA), que regulamenta a produção orgânica, no cultivo de forrageiras, devese assegurar a diversidade de espécies. Consórcios, que envolvam ao menos parte do sistema forrageiro com espécies perenes, são recomendados, à medida que contribuem de forma mais adequada para a conservação do solo. Assim, prevendo-se o uso constante da área no decorrer do ano agrícola, em área com capim elefante, espécies como o azevém (Lolium multiflorum Lam.) e o trevo vermelho (Trifolium pratense L.), por apresentarem bom rendimento forrageiro e elevado valor nutritivo, podem contribuir para a constituição de consórcio viável.

Nesse sentido, com o presente trabalho, teve-se o objetivo de avaliar variáveis da massa de forragem e a carga animal de pastagens de capim elefante, submetidas aos sistemas de produção agroecológico e convencional, utilizadas por vacas em lactação, no decorrer do ano agrícola.

\section{MATERIAL E MÉTODOS}

O experimento foi conduzido no Laboratório de Bovinocultura de Leite do Departamento de Zootecnia da Universidade Federal de Santa Maria (UFSM), entre julho de 2010 e maio de 2011, totalizando 304 dias, em área experimental localizada na região fisiográfica denominada Depressão Central do Rio Grande do Sul, com altitude de $95 \mathrm{~m}$, latitude $29^{\circ} 43^{\prime}$ Sul e longitude $53^{\circ} 42^{\prime}$ Oeste. O solo é classificado como Argissolo Vermelho Distrófico Arênico, pertencente à unidade de mapeamento São Pedro (STRECK et al., 2002). O clima da região é o Cfa (subtropical úmido), conforme classificação de Köppen. As médias climáticas para temperatura diária e precipitação mensal média são de $18,5^{\circ} \mathrm{C}$ e $141,8 \mathrm{~mm}$, respectivamente. No período experimental, as médias foram de $18,1^{\circ} \mathrm{C}$ e $182,1 \mathrm{~mm}$, respectivamente. Destacando-se que, para precipitação pluviométrica, houve excedente nos meses de julho, setembro e novembro, e déficits em outubro, dezembro e março. Durante os meses de junho, julho e agosto, foram registradas três, seis e seis geadas, respectivamente.
Foram utilizadas duas áreas experimentais, subdivididas em dois piquetes de 0,12 ha cada. No sistema agroecológico, seguindo-se os princípios contidos na Instrução Normativa no 46/2011 do Ministério da Agricultura, Pecuária e Abastecimento, o capim elefante, cv. Merckeron Pinda, foi estabelecido em linhas afastadas a cada $3 \mathrm{~m}$. Em maio, nas entrelinhas, realizou-se a semeadura a lanço do azevém, cv. Comum, à razão de $30 \mathrm{~kg}$ $\mathrm{ha}^{-1}$ de sementes viáveis, e do trevo vermelho, cv. Estanzuela 116, à razão de $8 \mathrm{~kg} \mathrm{ha}^{-1}$, não sendo realizado qualquer preparo do solo. No período estival, permitiu-se o desenvolvimento de espécies de crescimento espontâneo. A adubação utilizada, correspondendo a $150-90-65 \mathrm{~kg} \mathrm{ha}^{-1}$ ano $^{-1}$ de N, $\mathrm{P}_{2} \mathrm{O}_{5} \mathrm{e}$ $\mathrm{K}_{2} \mathrm{O}$, foi constituída por esterco bovino, coletado em mangueira de espera, com $35 \%$ de matéria seca (MS). A composição química, com base na MS, foi de 1,2; 0,45 e $0,62 \%$ de $\mathrm{N}, \mathrm{P}_{2} \mathrm{O}_{5}$ e $\mathrm{K}_{2} \mathrm{O}$, respectivamente. As fertilizações foram feitas em duas aplicações, sendo uma no período hibernal $(30 \%)$ e outra no estival (70\% do volume).

No sistema convencional, o capim elefante foi estabelecido singularmente em linhas afastadas a cada 1,4 m. No mês de setembro, fez-se a adubação de base, conforme análise do solo, sendo usados em média 40-90-65kg ha-1 de $\mathrm{N}, \mathrm{P}_{2} \mathrm{O}_{5}$ e $\mathrm{K}_{2} \mathrm{O}$, respectivamente; a adubação nitrogenada usada em cobertura, a base de ureia, foi de $110 \mathrm{~kg}$ de $\mathrm{N} \mathrm{ha}^{-1}$, fracionada em quatro aplicações. No final do mês de setembro foi realizada roçada no capim elefante de ambos os sistemas.

O método de pastejo adotado foi $\mathrm{o}$ rotacionado, com tempo de ocupação de um dia. O critério para se iniciar o pastejo no período estival, em ambos os sistemas forrageiros, foi a altura do capim elefante, quando esse apresentava entre 1 e 1,2m; no período hibernal (na pastagem agroecológica), o critério adotado foi a altura do azevém (aproximadamente $20 \mathrm{~cm}$ ). Antecedendo a entrada dos animais, em cada pastejo, foram feitas amostragens, determinando-se a massa de forragem mediante técnica com dupla amostragem (MANNETJE, 2000). O capim elefante foi cortado a $50 \mathrm{~cm}$ do solo. No sistema sob manejo agroecológico, nas entrelinhas, os cortes foram feitos rente ao solo. A carga animal na pastagem convencional foi calculada com base na biomassa de lâminas foliares do capim elefante, à razão de $4 \%$ de forragem seca por $100 \mathrm{~kg}$ de peso vivo; na pastagem sob manejo agroecológico, usou-se a mesma metodologia para o capim elefante, que ocupou aproximadamente um terço da área; nas entrelinhas, a carga animal foi calculada com 
oferta de $8 \mathrm{~kg}$ de forragem seca por $100 \mathrm{~kg}$ de peso vivo. Como animais experimentais, foram usadas vacas da raça Holandesa com peso médio de $543 \mathrm{~kg}$ e produção de leite de $20,43 \mathrm{~kg} \mathrm{dia}^{-1}$, que receberam complementação alimentar diária à razão de $0,9 \%$ do peso corporal.

A taxa de acúmulo de MS das pastagens foi determinada pela diferença entre a massa de forragem do pós e do pré-pastejo, dividindo o resultado pelo número de dias compreendido entre os ciclos de pastejo. A taxa de desaparecimento de forragem foi calculada pela diferença entre a massa de forragem do pré e do pós-pastejo, transformada em porcentagem. Essas variáveis foram avaliadas a partir do pastejo realizado em dezembro, após a roçada efetuada no final do pastejo realizado em setembro.

Para a análise da proteína bruta, foram coletadas amostras simulando cada pastejo, mediante observação do comportamento ingestivo das vacas, uma em cada piquete, no início (entrada dos animais) e no final (antecedendo a retirada dos animais). Após a secagem, fez-se a mistura proporcional dos materiais retirados no início e final do pastejo (amostra composta). O teor de nitrogênio total foi determinado pelo método de Kjeldahl (AOAC, 1984), sendo utilizado para o cálculo de proteína bruta.

$\mathrm{O}$ delineamento experimental foi $\mathrm{O}$ inteiramente casualizado, com dois tratamentos (sistemas convencional e agroecológico), duas repetições (piquetes), com medidas repetidas no tempo (ciclos de pastejo). Para a análise, consideraram-se os valores médios dos pastejos no decorrer do ano agrícola. Os dados foram submetidos à análise de variância e as médias comparadas pelo teste $\mathrm{F}$ em nível de 5\% de probabilidade do erro (SAS, 1997).

\section{RESULTADOS E DISCUSSÕES}

Durante o período experimental, foram conduzidos oito ciclos de pastejo no sistema agroecológico e sete no sistema convencional (Tabela 1), tendo-se obtido intervalo médio entre os pastejos de 38 e 43 dias, respectivamente. Esses períodos são considerados elevados e devem-se, em parte, à roçada efetuada em setembro. Considerando-se os pastejos conduzidos entre dezembro e maio, a média dos intervalos foi de 30 dias para ambos os sistemas. Segundo DERESZ et al. (2001), tempos curtos de ocupação de 2 a 3 dias, associados a períodos de descanso de 30 dias, estão relacionados à melhor qualidade da forragem e desempenho animal.

Quanto à massa de forragem de pré-pastejo da pastagem, houve similaridade entre os sistemas, considerando o valor médio entre as avaliações. A diferença $(\mathrm{P} \leq 0,05)$ observada para a massa de forragem do capim elefante deve-se à composição das pastagens, havendo maior produção no sistema convencional. Esse resultado deve-se ao maior potencial de produção de forragem do capim elefante, em relação às demais espécies utilizadas no sistema sob manejo agroecológico. Em ambos os sistemas, destacam-se os valores elevados de capim elefante (entre junho e setembro), considerando-se que se trata de uma espécie de ciclo estival. A proporção de lâminas nesse período foi elevada, mesmo no pastejo efetuado em agosto (sistema agroecológico). Esse comportamento do capim elefante no período hibernal, no qual, tradicionalmente, há escassez de forragem, pode-se constituir em estratégia importante em muitas regiões do sul do País, notadamente se ocorrerem invernos amenos. Também STEINWANDTER et al. (2009), conduzindo trabalho, na mesma Região, com capim elefante consorciado com trevo branco e amendoim forrageiro, respectivamente, usando $100 \mathrm{~kg}$ de $\mathrm{N} \mathrm{ha}^{-1}$ ano $^{-1}$, verificaram produções de forragem elevadas no período hibernal $\left(4,4 \mathrm{t} \mathrm{ha}^{-1}\right.$ para pastagem, sendo que $70 \%$ desse valor foi constituído por capim elefante).

Para o valor médio da massa de lâminas foliares do capim elefante, houve diferença $(P \leq 0,05)$, naturalmente esperada, devido à composição da pastagem, com menor participação dessa forrageira na pastagem sob manejo agroecológico. Os valores médios são superiores ao observado por STEINWANDTER et al. (2009), de 0,96t ha ${ }^{-1}$, em pastagem de capim elefante consorciadas com distintas leguminosas.

Comparando-se os valores da composição estrutural, houve similaridade entre os sistemas forrageiros. O valor médio de lâmina foliar de 50,51\% é superior ao verificado por AZEVEDO JUNIOR et al. (2012), de 44,5\%, para o capim elefante submetido ao consórcio com diferentes leguminosas e avaliado no decorrer do ano agrícola.

Quanto à forragem presente na entrelinha do sistema agroecológico, observa-se que a participação média da leguminosa em seis dos oitos pastejos foi expressiva. Mesmo considerando toda área, o valor de $21 \%$ de participação na pastagem está próximo da recomendação de ALVARENGA et al. (1995), considerado como adequado à sustentabilidade do sistema forrageiro. Nos pastejos efetuados entre fevereiro e maio, houve um declínio acentuado do trevo vermelho, devido às elevadas temperaturas e baixa umidade verificadas entre dezembro e março. Esse comportamento implicou 
Tabela 1 - Massa de forragem de pré-pastejo e composição estrutural do capim elefante (CE) sob manejo agroecológico (Agro) e convencional (Conv). Santa Maria, RS, 2010-2011.

\begin{tabular}{|c|c|c|c|c|c|c|c|c|c|c|c|}
\hline \multirow{2}{*}{ Parâmetro } & \multirow{2}{*}{ Sistema } & \multicolumn{8}{|c|}{ 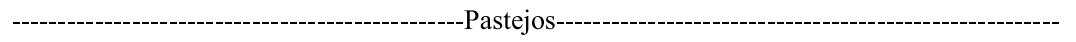 } & \multirow{2}{*}{ Média $^{1}$} & \multirow{2}{*}{$\begin{array}{l}\text { CV } \\
(\%)\end{array}$} \\
\hline & & $1(15 / j u l)$ & 2(18/ago) & $3(14 /$ set $)$ & $4(15 / \mathrm{dez})$ & $5(20 /$ jan $)$ & $6(14 / \mathrm{fev})$ & $7(18 /$ mar $)$ & $8(15 / \mathrm{mai})$ & & \\
\hline & & ------------ & --------- & -Massa de & forragem ( $\mathrm{k}$ & g de MS ha & 1) ---------- & ------------- & ------------- & & \multirow{3}{*}{8,43} \\
\hline \multirow{2}{*}{ Pastagem } & Agro & 6003 & 3050 & 5072 & 263 & 3076 & 5452 & 3519 & 3224 & 3762 & \\
\hline & Conv & 6587 & - & 5792 & 852 & 3367 & 5611 & 6205 & 5824 & 4891 & \\
\hline \multirow{2}{*}{$\mathrm{CE}$} & Agro & 5391 & 2535 & 4285 & 263 & 2189 & 4113 & 2711 & 1898 & $2923^{b}$ & \multirow{2}{*}{10,42} \\
\hline & Conv & 6587 & - & 5792 & 952 & 3367 & 5611 & 6206 & 5824 & $4891^{\mathrm{a}}$ & \\
\hline \multirow{2}{*}{ LF CE } & Agro & 1755 & 834 & 1409 & 156 & 1240 & 2324 & 1720 & 782 & $1277^{\mathrm{b}}$ & \multirow{2}{*}{10,10} \\
\hline & Conv & 2340 & - & 1624 & 719 & 2215 & 3617 & 3743 & 2622 & $2397^{a}$ & \\
\hline \multirow[t]{2}{*}{$\mathrm{EL}$} & Agro & 612 & 515 & 787 & 435 & 887 & 1339 & 1864 & 1325 & 838 & 6,09 \\
\hline & & ------- & ----- & \multicolumn{6}{|c|}{ 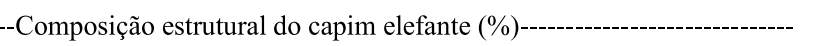 } & & \multirow{3}{*}{12,35} \\
\hline \multirow{2}{*}{ LF CE } & Agro & 50,95 & 14,85 & 20,50 & 77,45 & 60,70 & 69,60 & 51,50 & 42,95 & 48,56 & \\
\hline & Conv & 40,30 & - & 35,15 & 68,95 & 63,50 & 70,40 & 49,75 & 39,20 & 52,46 & \\
\hline \multirow{2}{*}{$\begin{array}{l}\mathrm{CO}+\mathrm{BA} \\
\mathrm{CE}\end{array}$} & Agro & 36,05 & 50,85 & 52,70 & 14,80 & 31,35 & 30,40 & 35,90 & 48,35 & 37,55 & \multirow{2}{*}{11,65} \\
\hline & Conv & 48,65 & - & 25,55 & 18,65 & 35,05 & 21,95 & 36,80 & 53,95 & 34,37 & \\
\hline \multirow{3}{*}{ MM CE } & Agro & 12,95 & 34,35 & 26,80 & 7,80 & 7,95 & - & 12,60 & 8,65 & 15,87 & \multirow{2}{*}{30,37} \\
\hline & Conv & 11,00 & - & 39,30 & 12,40 & 2,90 & 7,6 & 13,45 & 6,90 & 14,16 & \\
\hline & & & --- & ----Forra & gem presente & na entrelin & $(\%)$ & ------. & ---------- & \multirow{2}{*}{\multicolumn{2}{|c|}{51,73}} \\
\hline $\mathrm{AZ}$ & Agro & 44,95 & 52,25 & 56,00 & - & - & - & - & - & & \\
\hline $\mathrm{TV}$ & Agro & 27,75 & 17,15 & 18,75 & 61,60 & 56,95 & 7,60 & - & - & 31,96 & \\
\hline MM EL & Agro & 14,15 & 20,35 & 12,00 & 23,25 & 9,95 & 17,15 & 14,05 & 13,40 & 15,78 & \\
\hline Paspalum & Agro & - & - & - & - & 26,10 & 56,95 & 49,7 & 75,95 & 52,17 & \\
\hline Outras & Agro & 15,65 & 10,20 & 13,25 & 14,85 & 7,00 & 18,30 & 36,30 & 10,70 & 16,03 & \\
\hline
\end{tabular}

${ }^{1}$ Médias seguidas por letras distintas entre sistemas, nas colunas, diferem entre si pelo teste $\mathrm{F}$ a $5 \%$ de probabilidade do erro. LF=lâmina foliar; $\mathrm{EL}=$ entrelinha; $\mathrm{CO}+\mathrm{BA}=$ colmo+bainha; $\mathrm{MM}=$ material morto; $\mathrm{AZ}=$ azevém; $\mathrm{TV}=$ trevo vermelho; $\mathrm{CV}=$ coeficiente de variação.

aumento na participação de Paspalum ssp. e outras espécies como milhã (Digitaria adscendens (H.B.K) Henrard) e o papuã (Urochloa plantaginea (Link) Hitchc). Esse resultado confirma a ação que as leguminosas exercem no controle de espécies de crescimento espontâneo (AZEVEDO JUNIOR et al., 2012).

Avaliando-se a participação das distintas espécies na entrelinha, no decorrer do ano agrícola, confirma-se a possibilidade de consórcio azevém e trevo vermelho para o período hibernal e do potencial das espécies de crescimento espontâneo no período estival, como o Paspalum ssp., indicando o potencial produtivo e de persistência dessas gramíneas (KAMINSKI et al., 1998).
Quanto à taxa de desaparecimento de forragem do capim elefante (Tabela 2), o maior $(\mathrm{P} \leq 0,05)$ valor verificado no sistema agroecológico deve-se à maior preferência dos animais por essa forrageira, se comparada com as espécies de crescimento espontâneo, que tiveram participação expressiva nos pastejos efetuados entre dezembro e maio, com taxa de desaparecimento inferior. Para lâmina foliar do capim elefante, as taxas foram similares entre os sistemas. $\mathrm{O}$ valor residual dessa fração, próximo a $35 \%$, fundamental para o rebrote da cultura, permitindo que um novo pastejo fosse feito como recomendado, próximo de 30 dias (DERESZ et al., 2001), aponta que houve acerto no manejo utilizado em ambos os sistemas. 
Tabela 2 - Taxas de desaparecimento e de acúmulo de forragem em sistemas sob manejo agroecológico (Agro) e convencional (Conv). Santa Maria, RS, 2010 - 2011.

\begin{tabular}{|c|c|c|c|c|}
\hline Sistema & Pastagem & $\mathrm{CE}$ & LF CE & EL \\
\hline Agro & $487^{\mathrm{a}}$ & $557^{\mathrm{a}}$ & 662 & 250 \\
\hline Conv & $33,6^{\mathrm{b}}$ & $33,6^{\mathrm{b}}$ & 63,5 & - \\
\hline $\mathrm{CV}(\%)$ & 16,0 & 14,0 & 9,4 & - \\
\hline Agro & 115 & 96 & 61 & 24 \\
\hline Conv & 132 & 132 & 77 & - \\
\hline $\mathrm{CV}(\%)$ & 14,5 & 14,1 & 19,5 & - \\
\hline Sistema & Pastagem & $\mathrm{CE}$ & LF CE & EL \\
\hline Agro & $48,7^{\mathrm{a}}$ & $55,7^{\mathrm{a}}$ & 66,2 & 25,9 \\
\hline Conv & $33,6^{\mathrm{b}}$ & $33,6^{\mathrm{b}}$ & 63,5 & - \\
\hline $\mathrm{CV}(\%)$ & 16,0 & 14,0 & 9,4 & - \\
\hline Agro & 115 & 96 & 61 & 24 \\
\hline Conv & 132 & 132 & 77 & - \\
\hline CV (\%) & 14,5 & 14,1 & 19,5 & - \\
\hline
\end{tabular}

Médias seguidas por letras distintas entre sistemas, nas colunas, diferem entre si pelo teste $\mathrm{F}$ a $5 \%$ de probabilidade do erro. $\mathrm{CE}=$ capim elefante; $\mathrm{LF}=$ lâmina foliar; $\mathrm{EL}=$ entrelinha; $\mathrm{CV}=$ coeficiente de variação.

Considerando-se a taxa de desaparecimento da forragem com base na porcentagem do peso vivo, os valores foram de 3,53 e $2,88 \%$. O maior valor, observado no sistema agroecológico, deve-se, em parte, às características dessa pastagem, implicando maiores perdas, devido à estrutura das forrageiras presentes na entrelinha, como o azevém, o trevo vermelho, o Paspalum ssp., de porte mais baixo, que sofrem maior impacto devido ao pisoteio, em comparação à estrutura mais ereta do capim elefante (MEINERZ et al., 2011), formando touceiras, com os animais deslocando-se entre elas. Relação similar, com menor valor da taxa de desaparecimento para a pastagem de capim elefante em consórcio com espécies de ciclo hibernal e estival em relação ao estabelecido singularmente, também foi verificada por MEINERZ et al. (2011), obtendo valores de 2,63 e $2,19 \%$, respectivamente.

Para taxa de acúmulo diário de MS da pastagem (Tabela 2), os valores foram similares entre os sistemas; Para o capim elefante, houve diferença $(P \leq 0,05)$, com maior valor para o sistema convencional com cultivo exclusivo de capim elefante, devido ao maior desenvolvimento dessa forrageira em relação às demais que constituíram a pastagem sob manejo agroecológico. Ressalta-se, no entanto, que a produtividade do capim elefante no sistema agroecológico foi maior, considerando a área ocupada. Possivelmente, a disposição das touceiras em linhas, permitindo melhor captação de luz e o sinergismo com outras forrageiras, especialmente a leguminosa, tenha contribuído para esse resultado.

Com relação à taxa de lotação (Tabela 3), não houve diferença entre os sistemas, sendo que os valores médios são similares aos verificados por MEINERZ et al. (2011), de 2,5 e 3,3 UA/ha/dia, trabalhando com capim elefante manejado de forma similar ao do presente trabalho. Valores entre 3,28 e 3,60UA ha-1 dia $^{-1}$ foram observados na mesma Região por AZEVEDO JUNIOR et al. (2012), avaliando capim elefante em consórcio com diferentes forrageiras, submetido ao pastejo com vacas em lactação.

Quanto ao teor de proteína bruta da forragem de capim elefante, não houve diferença entre os sistemas. Parte desse resultado deve-se aos valores elevados de proteína bruta do capim elefante 
Tabela 3 - Proteína bruta e taxa de lotação em pastagens de capim elefante, manejadas de forma convencional (Conv) e agroecológica (Agro). Santa Maria, 2010 - 2011.

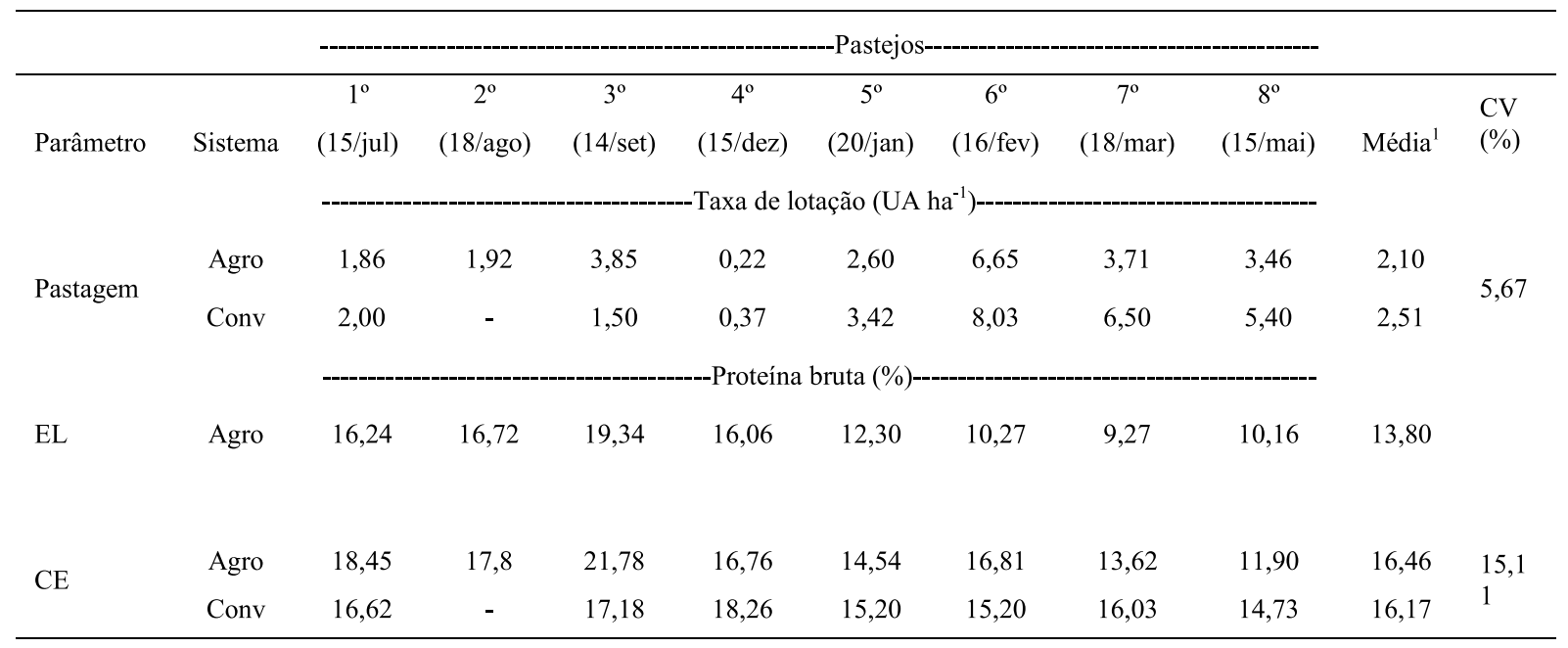

${ }^{1}$ Médias seguidas por letras distintas entre sistemas, nas colunas, diferem entre si pelo teste $\mathrm{F}$ a $5 \%$ de probabilidade do erro. CE= capim elefante; $\mathrm{LF}=$ lâmina foliar; $\mathrm{EL}=$ entrelinha; $\mathrm{CV}=$ coeficiente de variação.

nos pastejos efetuados no período hibernal, em ambos os sistemas, como observado por OLIVO et al. (2010), que obtiveram, nas avaliações realizadas em setembro e outubro, médias de 27,0 e $27,3 \%$ de proteína bruta para o capim elefante, quando utilizado em consórcio com trevo branco e amendoim forrageiro, respectivamente. Esse resultado com menor teor de proteína bruta no período estival deve-se ao maior desenvolvimento da planta nessa época, elevando, consequentemente, os teores de MS, parede celular, lignina, fibra e celulose, que normalmente guardam relação inversa com o teor de proteína. OLIVO et al. (2007) observaram resultados similares, com valores de 17,17 e 13,37\% para os períodos hibernal e estival, respectivamente, com capim elefante adubado com $150 \mathrm{~kg}$ de $\mathrm{N} \mathrm{ha}^{-1}$ ano $^{-1}$.

Considerando a forragem presente nas entrelinhas, os valores de proteína são maiores nos pastejos efetuados entre julho e setembro, devido à participação do azevém e do trevo vermelho, que, como espécies de ciclo hibernal, apresentam, normalmente, melhor valor nutritivo, se comparados com espécies de ciclo estival (STOBBS, 1973).

\section{CONCLUSÃO}

A utilização do capim elefante sob pastejo rotacionado, submetido aos sistemas convencional ou agroecológico são estratégias viáveis para a região Sul do País, para alimentação de vacas em lactação. No sistema agroecológico, há melhor distribuição de forragem no decorrer do ano agrícola. Os valores elevados de proteína da forragem do capim elefante no período hibernal apontam que essa forrageira mantém a qualidade nessa época, embora haja menor produção de biomassa de lâminas foliares.

\section{COMITÊ DE ÉTICA E BIOSSEGURANÇA}

Protocolo 23081016073/2011-27, parecer 113/2011

\section{REFERÊNCIAS}

ALVARENGA, R.C. et al. Características de alguns adubos verdes de interesse para a conservação e recuperação de solos. Pesquisa Agropecuária Brasileira, v.30, n.1, p.175-185, 1995. Disponível em: <http://webnotes.sct.embrapa.br/pdf/pab1995/ fevereiro/pab04_fev_95.pdf>. Acesso em: 25 maio, 2012.

ASSOCIATION OF OFFICIAL ANALYTICAL CHEMISTS (AOAC). Official methods of analysis. 14.ed. Arlington, USA, 1984. 1094p.

AZEVEDO JUNIOR, R.L. et al. Forage mass and the nutritive value of pastures mixed with forage peanut and red clover. Revista Brasileira de Zootecnia, v.41, n.4,p.827-834, 2012. Disponívelem: <http://dx.doi.org/10.1590/S1516-35982012000400002>. Acesso em: 30 maio, 2012. doi: 10.1590/S1516-35982012000400002.

DERESZ, F. et al. Influência de estratégias de manejo em pastagem de capim-elefante na produção de leite de vacas Holandês x Zebu. Arquivo Brasileiro de Medicina Veterinária e Zootecnia, v.53, n.4, p.1-10, 2001. Disponível em: <http://dx.doi.org/10.1590/ S0102-09352001000400018>. Acesso em: 20 maio, 2012. doi: S0102-09352001000400018.

MANNETJE, L.'t. Measuring biomass of grassland vegetation. In: MANNETJE, L'.T.; JONES, R.M. Field and 
laboratory methods for grassland and animal production Research. Cambridge: CABI, 2000. p.51-178.

KAMINSKI, J. et al. Resposta de biótipos da grama forquilha à calagem e à frequência de corte. Ciência Rural, v.28, n.4, p.581586, 1998. Disponível em: <http://dx.doi.org/10.1590/S0103$84781998000400008>$. Acesso em: 15 jan. 2013. doi: S010384781998000400008 .

MEINERZ, G.R. et al. Produção e valor nutritivo da forragem de capim-elefante em dois sistemas de produção. Revista Brasileira de Zootecnia, v.40, n.12, p.2673-2680, 2011. Disponível em: <http://www.scielo.br/pdf/rbz/v40n12/09.pdf>. Acesso em: 10 maio, 2012. doi: 10.1590/S1516-35982011001200009.

OLIVO, C.J. et al. Produtividade e valor nutritivo de pasto de capim elefante manejado sob princípios agroecológicos. Revista Brasileira de Zootecnia, v.36, n.6, p.1729-1735, 2007. Disponível em: <http://dx.doi.org/10.1590/S151635982007000800004>. Acesso em: 12 maio, 2012. doi: 10.1590/ S1516-35982007000800004

OLIVO, C.J. et al. Contribuição dos componentes e composição química de pastagens em sistemas forrageiros constituídos por diferentes leguminosas. Ciência Rural, v.40, n.12, p.25352540, 2010. Disponível em: <http://dx.doi.org/10.1590/S010384782010001200016>. Acesso em: 08 maio, 2012. doi: 10.1590/ S0103-84782010001200016.

SAS INSTITUTE. SAS user'sguide: statistics. Version 6.11. Cary, North Carolin, 1997. 1187p.

STEINWANDTER, E. et al. Produção de forragem em pastagens consorciadas com diferentes leguminosas sob pastejo rotacionado. Acta Scientiarum Animal Sciences, v.31, n.2, p.131-137, 2009. Disponível em: <http://www.periodicos.uem.br/ojs/index.php/ ActaSciAnimSci/article/view/6238/6238>. Acesso em: 20 maio, 2012. doi: : 10.4025/actascianimsci.v31i2.6238.

STOBBS, T.H. The effect of plant structure on the intake of tropical pasture. 2. Differences in sward structure, nutritive value, and bite size of animals grazing Setaria anceps and Chloris gayana at various stages of growth. Journal of Agricultural Research, v.24, n.6, p.821-829, 1973.

STRECK, E.V. et al. Solos do Rio Grande do Sul. Porto Alegre: EMATER/RS - Universidade Federal do Rio Grande do Sul, 2002. $126 \mathrm{p}$. 